Publisher homepage: www.universepg.com, ISSN: 2663-6913 (Online) \& 2663-6905 (Print)

\title{
Patterns of Extended-Spectrum $\beta$-Lactamase Producing Uropathogens Detection in Tertiary Care Hospital of Bangladesh
}

\author{
Abdullah Akhtar Ahmed ${ }^{1,2}$, S.M. Ali. Hasan ${ }^{3}$, Nusrat Akhtar Juyee ${ }^{4}$, Md. Shahidul Islam ${ }^{5}$ and \\ Mohammad Zakerin Abedin ${ }^{1 *}$
}

${ }^{1}$ Dept. of Microbiology, Khwaja Yunus Ali University, Siragjanj, Bangladesh; ${ }^{2}$ Dept. of Microbiology, Khwaja Yunus Ali Medical College \& Hospital, Siragjanj, Bangladesh; ${ }^{3}$ Dept. of Gastroenterology, Bangabandhu Sheikh Mujib Medical University, Dhaka, Bangladesh; ${ }^{4}$ Dept. of Microbiology and Immunology, Bangabandhu Sheikh Mujib Medical University, Dhaka, Bangladesh; ${ }^{5}$ Dept. of Biochemistry and Molecular Biology, University of Chittagong, Chittagong, Bangladesh.

*Correspondence: zakerin.du2016@gmail.com (Mohammad Zakerin Abedin, Assistant Professor and Head, Dept. of Microbiology, Khwaja Yunus Ali University, Sirajganj, Bangladesh).

\begin{abstract}
It is a great concern that extended-spectrum $\beta$-lactamase (ESBL) and non-ESBL uropathogenic microorganisms have been worldwide illustrated to increase multidrug resistance. To study the prevalence and patterns of uropathogens, and antimicrobial susceptibilities profiles of ESBL and non-ESBL producing bacterial infection in a tertiary level health service center of Bangladesh. The prevalence of ESBL producing uropathogens and their antimicrobial resistance patterns were identified in 176 isolates from patients with UTI. ESBL and non-ESBL producing bacterial isolates and their antibiotic sensitivity and resistance patterns were distinguished from the 176 patients of suspected urinary tract infection. The Double-disc diffusion test was done to determine the presence of ESBL-producing bacterial strains. The most widely ESBL positive uropathogen was Escherichia coli (87\%), followed by Pseudomonas aeruginosa, (6.8\%), Enterococcus spp. (3.4\%), Acinetobacter spp. (2.5\%) and non-ESBL positive E. coli (41.4), Staphylococcus saprophyticus (25.9\%), Pseudomonas aeruginosa (17.2\%), Staphylococcus aureus (10.3\%), and Klebsiella pneumoniae (5.2\%). The current investigation found most frequently Escherichia coli in both ESBL and non-ESBL uropathogen group as $87 \%$ and $41.4 \%$ respectively. Generally, a large number of antibiotic resistance patterns and ESBL producing common bacterial isolates were found in this study which increases the public health problem. Therefore, for safe human life, we ought to be taking appropriate action against the threat.
\end{abstract}

Keywords: Prevalence, ESBL, Non-ESBL, Uropathogens, Tertiary region, and Antimicrobial patterns.

\section{INTRODUCTION:}

It has been alarmingly noticed that the infection of the urinary tract affects approximately. Around more than 150 million people each year are infected by bacterial pathogens in both genders. Urinary tract infection (UTI) is the second most common infection and is responsible for nearly seven million physician services per year (Akram et al., 2007).

UniversePG I www.universepg.com
The patterns of the diseases and frequency of infection are related to age and sex. Among uropathogens, E. coli are found responsible for $80 \%$ of community-acquired UTI and $40 \%$ of healthcareassociated UTI. Other uropathogens include Proteus spp, Staphylococcus, and Klebsiella spp. Enterococcus and Acinetobacter (Goering et al., 2004). Astonishingly, uropathogens found to alternate their physiological characteristics to prompt multidrug 
resistance (Ronald et al., 2003). Enhancing the tendency of developing antibiotic resistance among uropathogens is a global problem (Mathai et al., 2000; Sarker et al., 2019). The uropathogens produce extended-spectrum $\beta$-lactamase (EBSL) enzymes through which they hydrolyze oxyimino $\beta$ lactam compounds and it is one of the prime factors contributing to highly decrease antimicrobial susceptibility against $\beta$-lactam antibiotics (Gniadkowski et al., 2001).

The rate of multidrug resistance increases due to improper treatment of UTI caused by the ESBL and non-ESBL uropathogenic bacteria (Du et al., 2002). For the therapy of infections with antibiotics due to ESBL and non-ESBL-producing uropathogens is still a great challenge to solve the risk factors, treatment options, and infection control measures for its infection (Paterson et al., 1999). It has been a considerable problem with appropriate antimicrobial therapy due to ESBL and non-ESBL positive uropathogens. The point of this investigation was to observe patterns and prevalence of antimicrobial susceptibility in patients of Khwaja Yunus Ali Medical College \& Hospital in the tertiary region of Bangladesh.

\section{MATERIALS AND METHODS:}

Sample Collection - The study was carried on 589 non-consecutive and non-duplicate midstream cleancatch urine samples. The specimens were collected from the patients aseptically and processed at the microbiology laboratory of Khwaja Yunus Ali Medical College \& Hospital Laboratory Services Department from January 2020 to June 2020.

For the isolation and identification of bacterial isolates, we conducted the following standard bacteriological technique (Ahmed et al., 2016). For these purposes, the following dehydrated culture media were used namely Blood agar, MacConky agar, XLD, TSI, Urea, and Citrate. Urine samples

Table 1: Details on antibiotics used in this study

\begin{tabular}{|c|c|c|}
\hline Antibiotic group & Antibiotic name & Concentration $(\boldsymbol{\mu g}$ /disc) \\
\hline$\beta$-lactam antibiotic & Amoxicillin: (AML) & $20 \mu \mathrm{g}$ \\
\hline$\beta$-lactam/ $\beta$-lactamase inhibitors combination & Amoxiclave (AMC) & $20 \mu \mathrm{g}+10 \mu \mathrm{g}$ \\
\hline Aminoglycosides & Amikacin (AK) & $30 \mu \mathrm{g}$ \\
\hline Macrolide & Azithromycin (AZM) & $15 \mu \mathrm{g}$ \\
\hline
\end{tabular}

showing significant bacterial growth, of >105 colony-forming units $(\mathrm{CFU} / \mathrm{mL})$ with a single type of bacteria isolates, were considered uropathogens.

Testing for the ESBL Production - The identification of ESBLs production by 176 uropathogens out of 589 urine samples was conducted by a modified double-disc synergism test (Ahmed et al., 2017). Bacterial suspension of $0.5 \mathrm{McF}$ arland standards was plated in Muller-Hinton agar with Amoxycillinclavulanic acid $(30 \mu \mathrm{g})$ disc in between and $20 \mathrm{~mm}$ apart from Ceftazidime $(30 \mu \mathrm{g})$ and Ceftriaxone (30 $\mu \mathrm{g})$ discs. Expansion of the zone of inhibition around Ceftriaxone and/or ceftazidime disc towards the amoxicillin-clavulanic acid disc was considered ESBL production.

Antimicrobial Susceptibility Test - Antimicrobial susceptibility testing (AST) for all isolates was conducted on commercially available common antibiotics disc. Information on these antibiotics and their concentrations are shown in Table 1.

All ESBL and non-ESBL producing uropathogens were studied for antimicrobial sensitivity using disc diffusion technique by "Kirby-Bauer method" on the culture medium of Mueller-Hinton agar (Oxoid, UK) and interpretations were recorded according to the guidelines of clinical and laboratory standard institute (CLSI-2010) (Rahman et al., 2019; Manoharan et al., 2011).

The following commercially available antibiotics discs were used in the sensitivity test namely amoxicillin $(20 \mu \mathrm{g})$, amoxiclav $(30 \mu \mathrm{g})$, amikacin $(30 \mu \mathrm{g})$, azithromycin $(15 \mu \mathrm{g})$, ceftriaxone $(30 \mu \mathrm{g})$, Ciprofloxacin $(5 \mu \mathrm{g})$, gentamicin $(30 \mu \mathrm{g})$, levofloxacin $(5$ $\mu \mathrm{g})$, nitrofurantoin $(30 \mu \mathrm{g})$, imipenem $(10 \mu \mathrm{g})$, meropenem $(10 \mu \mathrm{g})$. On each of the Mueller-Hinton agar plates was used only for five antibiotic disks and incubated aerobically at $37^{\circ} \mathrm{C}$ for 24 hours. 


\begin{tabular}{|c|c|c|}
\hline Third-generation cephalosporin & Ceftriaxone (CRO) & $30 \mu \mathrm{g}$ \\
\hline Cephalosporin & Cefuroxime (CXM) & $5 \mu \mathrm{g}$ \\
\hline Fluoroquinolones & Ciprofloxacin (CIP) & $30 \mu \mathrm{g}$ \\
\hline Aminoglycosides & Gentamycin (GM) & $5 \mu \mathrm{g}$ \\
\hline Fluoroquinolone & Levofloxacin (LEV) & $30 \mathrm{~g}$ \\
\hline Nitrofurans & Nitrofurantoin (NI) & $10 \mu \mathrm{g}$ \\
\hline Carbapenems & Imipenem (IPM) & $10 \mu \mathrm{g}$ \\
\hline Carbapenem & Meropenem (MEM) & \\
\hline
\end{tabular}

\section{RESULTS:}

A total of 176 uropathogens from 589 urine sample cultures of inpatients were identified during this study period. Among these uropathogens 118 strains produced ESBL maximum 62 (52.5\%) belonged to female patients while $56(47.5 \%)$ belonged to male patients. While non-ESBL producing uropathogens shown no great variation in sexual point. With regard to the age categories of patients, a total of 96 (54.5\%) samples were collected from adults, 66 (37.5\%) samples belonged to the elderly population, and $14(8 \%)$ were obtained from children. Demographic characteristics of patients (Table 2).

\section{ESBL Prevalence and Antimicrobial Suscepti- bility Profiles}

Phenotypic identification of ESBL production of 176 uropathogens isolates showed that 118 (67\%) of all bacterial isolates were confirmed to be ESBL producers, while $58(33 \%)$ isolates were non-ESBL producers. The E. coli was the most frequent uropathogen $(72 \%)$ followed by $P$. aeruginosa $(17.2 \%)$ and Staph. saprophyticus (8.5\%). 10 of 18 Pseudomonas spp. samples were negative, 04 of samples of Enterobacter spp. and 03 Acinetobacter spp. were positive. All 06 Staphylococcus aureus, 15 Staphylococcus saprophyticus and 03 Klebsiella spp samples were found to be ESBL negative (Table 3).

Table 2: Demographic data of study population

\begin{tabular}{|c|c|c|c|c|c|}
\hline \multirow{2}{*}{ Age category } & \multicolumn{2}{|c|}{ Male } & \multicolumn{2}{c|}{ Temale } \\
\cline { 2 - 5 } & $\begin{array}{c}\text { ESBL } \\
\text { Positive }\end{array}$ & $\begin{array}{c}\text { ESBL } \\
\text { Negative }\end{array}$ & $\begin{array}{c}\text { ESBL } \\
\text { Positive }\end{array}$ & $\begin{array}{c}\text { ESBL } \\
\text { Negative }\end{array}$ \\
\hline Children* & 05 & 04 & 03 & 02 & $14(8)$ \\
\hline Adults** & 22 & 14 & 43 & 17 & $96(54.5)$ \\
\hline Elderly*** & 29 & 13 & 16 & 08 & $66(37.5)$ \\
\hline Total (\%) & $56(47.5)$ & $31(53.4)$ & $62(52.5)$ & $27(46.6)$ & $176(100)$ \\
\hline
\end{tabular}

$*$ Children: $0-17$ years, $* *$ adults: $18-64$ years, $* * *$ elderly: $\geq 65$ years.

Table 3: Shows pattern of ESBL \& non-ESBL producing uropathogenic bacteria

\begin{tabular}{|c|c|c|c|c|c|c|c|c|}
\hline ESBL & $\begin{array}{c}\text { E. coli } \\
\mathbf{1 2 7}(\mathbf{7 2})\end{array}$ & $\begin{array}{c}\boldsymbol{K} . \\
\text { pneumonia } \\
\mathbf{0 3}(\mathbf{1 . 7})\end{array}$ & $\begin{array}{c}\boldsymbol{P} . \\
\text { aeruginosa } \\
\mathbf{1 8}(\mathbf{1 0 . 2})\end{array}$ & $\begin{array}{c}\text { Acenatobacter } \\
\mathbf{s p . ~} \mathbf{0 3}(\mathbf{1 . 7})\end{array}$ & $\begin{array}{c}\text { Enterococcus } \\
\text { sp. 04 (2.3) }\end{array}$ & $\begin{array}{c}\text { S. } \\
\text { aureus } \\
\mathbf{0 6}(\mathbf{3 . 4})\end{array}$ & $\begin{array}{c}\text { S. } \\
\text { saprophyticus } \\
\mathbf{1 5}(\mathbf{8 . 5})\end{array}$ & Total \\
\hline Positive & $103(87)$ & 00 & $08(6.8)$ & $03(2.5)$ & $04(3.4)$ & 00 & 00 & 118 \\
\hline Negative & $24(41.4)$ & $03(5.2)$ & $10(17.2)$ & 00 & 00 & $06(10.3)$ & $15(25.9)$ & 58 \\
\hline Total & 127 & 03 & 18 & 03 & 04 & 06 & 15 & 176 \\
\hline
\end{tabular}

The antibiotic susceptibility profile for ESBL-producing uropathogens is presented in Table 4. Among all antibiotics tested in this study, imipenem was UniversePG I www.universepg.com found the most active agent as $98 \%$ against $E$. coli isolates. Out of the 112 ESBL producing E. coli isolates, $99 \%$ were resistant to ampicillin, $67 \%$ to 
amoxicillin-clavulanic acid, and 36\% to gentamicin. The resistance rates for amikacin, azithromycin, ceftriaxone, and levofloxacin were $17 \%, 82 \%, 82 \%$, and $53 \%$, respectively. Additionally, $2 \%$ and $23 \%$ of the isolates were least resistant to imipenem and meropenem, respectively.

\section{DISCUSSION:}

Multidrug-resistant uropathogens expressing extended-spectrum $\beta$-lactamase pose worldwide serious challenges to clinicians for the therapeutic management of clinical cases in urinary tract infection (UTI). In our study, both males and females were the commonest pervasive of bacterial infections and $35 \%$ of sound healthy women were warning indications of UTIs (Rezwana et al., 2015).

The current study was embraced to demonstrate the presence of ESBL- producing uropathogen isolates in clinical samples of patients in the tertiary medical clinic of Bangladesh. The predominance of ESBLproducing pathogens was found to be $67 \%$. ESBL production occurred more frequently in E. coli (87\%) than $P$. aeruginosa (6.8\%), Enterococcus spp. (3.4\%) and Acinetobacter spp. (2.5\%). The non ESBL production occurred more frequently also in E. coli (41.4\%) than Staph saprophyticus (25.9\%), P. aeruginosa (17.2\%), S. aureus (10.3\%) and Klebsiella spp. $(5.2 \%)$.

This figure is high contrasted with the figure reported in a study completed in Khartoum State hospitals by Mekki et al., who recorded ESBL production among E. coli and Klebsiella species isolates as 53\%. Similarly, a few numbers of ESBL producing $E$. coli $(36 \%)$ and a greater number of nonESBL producing E. coli (64\%) were distinguished in Egypt during 2013-14 (Elsayed et al., 2017). The high ranges of 41.0 to 63.6 percent in E. coli were reported for the prevalence of the ESBL production in other studies in India (Grover et al., 2006).

E. coli are the most well-known uropathogens and considered as normal flora of the gastrointestinal and distal urogenital, but they can ascend the urethra and get access to the urinary tract. Explicit harmfulness factors found in E. coli permit it to hold fast to and attack have cells, produce poisons, use have supplements, and avoid the host's immune system (Abedin et al., 2020). ESBLs constitute a serious threat to the $\beta$-lactam therapy. Because of the difficulty in their detection by the current clinical methods, many of these bacterial isolates have been falsely reported to be susceptible to the widely used broad-spectrum $\beta$-lactams (MacKenzie et al., 2002). We found such an associated resistance with gentamicin (36\%) and the flouroquinolones (67\%). Varsha et al., reported $91.17 \%$ and $94.91 \%$ resistances respectively to gentamicin and ciprofloxacin in the ESBL producers (Gupta et al., 2007).

Compared with our previous studies done at Khwaja Yunus Ali Medical College \& Hospital in 2013, the current investigation found lower resistance rates for the majority of isolated $E$. coli were resistant to Meropenem (41.4\%) and Amikacin (42.3\%) followed by gentamicin (47.4\%), amoxiclav (56.9\%), Ciprofloxacin (57.8\%), (Ahmed et al., 2016). This decreased drug resistance indicates successfully coordinated monitoring of drug activity and usage. Overall, these findings indicate that ESBLs production in bacterial species differs greatly all over the world, and it rapidly changes from time to time and place to place.

\section{CONCLUSION:}

This study was illustrated to find out the prevalence and patterns of ESBL and non-ESBL producing uropathogens in clinical isolates from the tertiary level hospital of Bangladesh against commonly prescribed antibiotics. The prevalence of ESBL producing E. coli is $87 \%$. Multidrug resistance patterns were discovered to be altogether higher in ESBL (67\%) producer isolates when contrasted with non-ESBL $(33 \%)$ producer isolates. This finding highlights the importance of constant observing programming of multidrug resistance in our hospitals. It also showed the need for developing atempts to decrease the prevalence of ESBL producing uropathogens. ESBLs are clinically significant and patients infected with ESBL-producing uropathogens are vitally important to treat with appropriate antibiotics.

Finally, many studies had varied findings according to place and time casting doubt on their quality and making comparisons among them difficult. Subsequently, there is a requirement for normalization of observation methodology and routine surveillance in the country, alongside appropriate activities to abate the overall rate of resistance. 


\section{ACKNOWLEDGMENT:}

We are grateful to the Chairman of the Trusty Board and the Director of Khwaja Yunus Ali Medical College Hospital to carry out this study. We express gratitude toward Md. Abdul Karim and Mazharul Haque for assisting in laboratory work at the Department of Laboratory Services of Khwaja Yunus Ali Medical College \& Hospital, Sirjganj, Bangladesh.

\section{CONFLICTS OF INTEREST:}

No conflict of interest among the authors.

\section{REFERENCES:}

1. Abedin MZ, Faruque MO, Sifat Uz Zaman M, Nasim R, Hasan R, Jarin L, Islam R, and Uddin ME. (2020). Prevalence and In Vitro Antibiogram Patterns of Urinary Tract Pathogens in Rural Hospitals in Bangladesh. JCBPS, 3(10): 401-409. https://doi.org/10.24214/jcbps.B.10.3.40109

2. Ahmed AA et al. (2016). Antibiotic Sensitivity Pattern of Uropathogens at Khwaja Yunus Ali Medical College Hospital. KYAU Journal, 6(2): 610-613. https://doi.org/10.3329/kyamcj.v6i2.33737

3. Ahmed AA. Hossain MS, Aktar B, Juyee NA, Hasan SAM. (2017). Detection of Extended spectrum beta lactamases (ESBL) producing pathogens in Khwaja Yunus Ali Medical College Hospital. KYAU Journal. 2(1): 1-6.

4. Akram M, Shaid M, Khan AU. (2007). Etiology and antibiotic resistance patterns of community acquired urinary tract infection in JNNC Hospital Aligarh, India. Ann Clin Microbiol Antimicrob. 6: 4.

https://pubmed.ncbi.nlm.nih.gov/17378940/

5. Du B, Long Y, Liu H, Chen D, Liu D, Xu Y, et al. (2002). Extended-spectrum beta-lactamaseproducing Escherichia coli and Klebsiella pneumoniae bloodstream infection: risk factors and clinical outcome. Intensive Care Med. 28(12): 1718-23.

https://pubmed.ncbi.nlm.nih.gov/12447513/

6. Elsayed TI, Ismail HA, Elgamal SA, Gad AHA. (2017). The Occurrence of Multidrug Resistant E. coli which Produce ESBL and Cause Urinary Tract Infections. J Appl Microbiol Biochem, 1(2): 8 .

7. Goering RV, Dockrell HM, Zuckerman M, Wakelin D, Roitt IM, Mims C, et al. (2008).
Mims' Medical Microbiology. $4^{\text {th }}$ ed. Philadelphia: Mosby.

https://www.elsevier.com/books/mims-medicalmicrobiology-and-immunology/goering/978-07020-7154-6

8. Gniadkowski M. (2001). Evolution and epidemiology of extended spectrum b-lactamases (ESBL) and ESBL producing microorganisms. Clin Microbiol Infect. 7: 597-608. https://doi.org/10.1046/j.1198-743x.2001.00330.x

9. Grover SS et al. (2006). Phenotypic and genotypic detection of ESBL mediated cephalosporin resistance in $K$. pneumoniae: emergence of high resistance against cefepime, the fourth generation cephalosporin. J Infect, 53: 279-88. https://pubmed.ncbi.nlm.nih.gov/16488476/

10. Gupta V, Singla N, Chander J. (2007). Detection of ESBLs using third and fourth cephalosporins in double disc synergy test. Indian J Med Res. 126: $486-87$.

https://www.ijmr.org.in/temp/IndianJMedRes1265 486-5520681_152006.pdf

11. Mathai D, Lewis MT, Kugler KC, Pfaller MA, Jones RN. (2001). Antibacterial activity of 41 antimicrobials tested against over 2773 bacterial isolates from hospitalized patients with pneumonia: I-results from the Sentry Antimicrobial Surveillance Program. Diag Microbiol Infect Dis. 39(2): 105-16. https://europepmc.org/article/med/11248523

12. Manoharan A et al. (2011). Correlation of TEM, SHV and CTX-M extended-spectrum beta lactamases among Enterobacteriaceae with their in vitro antimicrobial susceptibility. Indian $\mathrm{J} \mathrm{Med}$ Microbiol, 29: 161-164. https://doi.org/10.4103/0255-0857.81799

13. Mekki AH, Hassan AN, Elsayed DE. (2010). Extended spectrum beta lactamases among multi drug resistant Escherichia coli and Klebsiella species causing urinary tract infections in Khartoum. Journal of Bacteriology Research, 2(3): 18-21.

14. MacKenzie FM, Miller FM CA, Gould IM. (2002). Comparison of screening methods for TEM and SHV derived ESBL detection. Clin Microbiol Infect. 8: 715-24. https://doi.org/10.1046/j.1469-0691.2002.00473.x

15. Paterson DL, Yu VL. Extended-spectrum betalactamases: a call for improved detection and control. Clin Infect Dis. 29(6): 1419-22. https://pubmed.ncbi.nlm.nih.gov/10585789/ 
16. Rahman MA, Ahmad T, Mahmud S, Uddin ME, and Ahmed R. (2019). Isolation, identification, and antibiotic sensitivity pattern of Salmonella spp from locally isolated egg samples. Am. J. Pure Appl. Sci., 1(1), 1-11. https://doi.org/10.34104/ajpab.019.019111

17. Ronald A. (2003). The etiology of urinary tract infection: traditional and emerging pathogens. Dis. Mon. 49: 71-82.

https://doi.org/10.1067/mda.2003.8
18. Rezwana H, Laila A, Abdus S. (2015). Prevalence and susceptibility of uropathogens: a recent report from a teaching hospital in Bangladesh. Biomed Cen Res Notes, 8: 416. https://doi.org/10.1186/s13104-015-1408-1

19. Sarker MKD, Sahabuddin M, Mosaib MG, and Alam MF. (2019). Antibiotic resistance analysis of Vibrio spp isolated from different types of water sources of Bangladesh and their characterization. Eur. J. Med. Health Sci., 1(4), 19-29. https://doi.org/10.34104/ejmhs.01929

Citation: Ahmed AA, Hasan SMA, Juyee NA, Islam MS, and Abedin MZ. (2021). Patterns of extendedspectrum $\beta$-lactamase producing uropathogens detection in tertiary care hospital of Bangladesh. Am. J. Pure Appl. Sci., 3(2), 29-34. https://doi.org/10.34104/ajpab.021.029034 @ @ 